Gibson, Stephen ORCID:

https://orcid.org/0000-0002-5648-7669, Crossland, Matthew and Hamilton, Jason (2018) Social citizenship and immigration: Employment, welfare and effortfulness in online discourse concerning migration to the UK. Qualitative Psychology, 5 (1). pp. 99-116.

Downloaded from: http://ray.yorksj.ac.uk/id/eprint/1718/

The version presented here may differ from the published version or version of record. If you intend to cite from the work you are advised to consult the publisher's version: http://psycnet.apa.org/psycarticles/2017-14094-001

Research at York St John (RaY) is an institutional repository. It supports the principles of open access by making the research outputs of the University available in digital form. Copyright of the items stored in RaY reside with the authors and/or other copyright owners. Users may access full text items free of charge, and may download a copy for private study or non-commercial research. For further reuse terms, see licence terms governing individual outputs. Institutional Repository Policy Statement

\title{
RaY
}

Research at the University of York St John

For more information please contact RaY at ray@yorksj.ac.uk 
Social citizenship and immigration: Employment, welfare and effortfulness in online discourse concerning migration to the UK.

\author{
Stephen Gibson, Matthew Crossland and Jason Hamilton \\ York St John University
}

\begin{abstract}
Author note
Stephen Gibson, Faculty of Health \& Life Sciences, York St John University;

Matthew Crossland, Faculty of Health \& Life Sciences, York St John University; Jason Hamilton, Faculty of Health \& Life Sciences, York St John University.

We would like to acknowledge the research assistance of Libby Johnstone, and comments on a previous version of the manuscript from Emma Anderson, Antonis Sapountzis and Maria Xenitidou.

Correspondence concerning this article should be addressed to Stephen Gibson, Faculty of Health \& Life Sciences, York St John University, Lord Mayor's Walk, York, YO31 7EX, UK. E-mail: s.gibson@yorksj.ac.uk
\end{abstract}




\begin{abstract}
The emerging social psychology of citizenship has made use of qualitative methods to explore people's understandings of issues such as polity membership and its associated rights and responsibilities. Whereas there is a burgeoning tradition of work on conceptions of polity membership, as well as on civil and political citizenship, relatively little work has thus far focussed on the concept of social citizenship - that aspect of citizenship which ensures that citizens have access to a basic income and standard of living. The present paper explores this in the context of debates over polity membership in relation to European Union (EU) immigration in the United Kingdom. Data collected from posts to an internet discussion forum are analysed using an approach informed by discursive and rhetorical psychologies. The findings indicate a range of arguments in relation to social citizenship that were used by posters to suggest that EU immigration would have a negative effect on the UK, and that such arguments frequently involved particular constructions of groups (e.g. 'immigrants', 'Romanians', 'Eastern Europeans') as likely to claim welfare benefits, or as low-skilled. However, pro-immigration arguments could equally involve outgroup derogation, but in these arguments posters constructed images of sub-groups of British citizens (e.g. 'white working class Brits') in order to suggest that immigration solved problems brought about due to the psychological deficiencies of these sub-groups. It is suggested that this constitutes a previously under-explored dimension of immigration discourse, and that renewed attention to social citizenship and welfare can bring these complexities into focus.
\end{abstract}




\section{Social citizenship and immigration: Employment, welfare and effortfulness in online discourse concerning migration to the UK.}

Citizenship is a concept with a rich tradition of scholarship in the wider social sciences, yet which has - until recently - received only sporadic attention within social psychology (for overviews, see Condor, 2011a; Stevenson, Dixon, Hopkins \& Luyt, 2015). As Condor (2011a) has noted, citizenship can be seen as a highly contested concept, and as such any attempt to define citizenship is fraught with difficulty. However, it is useful for present purposes to sketch an initial working definition of citizenship in order to delimit the sorts of issues that might be approached under the broad heading of citizenship. Isin and Wood's (1999) work is a useful starting point: they describe citizenship as 'both a set of practices (cultural, symbolic and economic) and a bundle of rights and duties (civil, political and social) that define an individual's membership in a polity' (p. 4, italics in original). Thus, polity membership can be seen to confer rights and responsibilities on citizens, and these can be withheld from those who are not citizens. Isin and Wood's distinction between civil, political and social rights and duties follows Marshall's (1950/1992) classic outline of civil, political and social citizenship. Such a distinction is instructive insofar as it highlights three core domains to which citizenship pertains: rights to political participation, such as voting in elections (political citizenship), rights to individual freedom, such as freedom of speech, movement and association (civil citizenship) and rights to a basic income and standard of living, where 'standard of living' not only connotes an economic standard, but also rights to participate in cultural activity (social citizenship).

As Condor (2011a) notes, some authors have argued that Marshall's tripartite distinction between civil, political and social citizenship is inadequate to capture the complexities of the multifaceted nature of the relationship between individual and polity. Of particular relevance for the present study, the notion of economic citizenship has been 
proposed as a way of capturing the nexus of relations surrounding employment and economic freedom. For example, following a well-established tradition of feminist critique of the gendered assumptions enshrined in welfare regimes, Kessler-Harris (2003) argued that existing ideas of social citizenship are in fact something of an obstacle to imagining alternative conceptions of citizenship which enable women to be accorded full citizenship. Kessler-Harris proposed economic citizenship as a conceptual vehicle for moving towards a less gendered idea of citizenship, and defined it thus:

'The achievement of economic citizenship can be measured by the possession and exercise of the privileges and opportunities necessary for men and women to achieve economic and social autonomy and independence.' (Kessler-Harris, 2003, p. 159) Included in Kessler-Harris's conception of economic citizenship are rights that others have suggested fall into one of Marshall's (1950/1992) original categories. For example, KesslerHarris argued that rights to pursue one's chosen occupation - which Marshall saw as a fundamental component of civil citizenship - should in fact be seen as part of economic citizenship.

For present purposes, we will retain the original distinction between political, civil and social citizenship, but an awareness of the way in which this distinction is contested at the level of theory is important as we turn to explore the way in which these issues are contested in popular discourse. A framework which draws on both Marshall's (1950/1992) and Isin and Wood's (1999) definitions provides a useful starting point for mapping some of the burgeoning literature on citizenship in social psychology, and for appreciating the specific contribution that qualitative methodological approaches can make to the psychological study of citizenship. Isin and Wood's (1999) definition allows for an expanded conception of citizenship beyond the formal legal arena to encompass more diffuse social-cultural practices. In exploring the way in which these practices are oriented to and enacted, qualitative 
approaches are well-placed to make a contribution to the study of citizenship. Isin and Wood suggest that for sociologists, citizenship can be understood as 'competent membership in a polity' (Isin \& Wood, 1999, p. 4). Gibson and Hamilton (2011) have argued that, for social psychologists influenced by recent developments in qualitative methodologies, this raises the question of how social actors themselves understand competent membership of a polity, and indeed how they deal with competing constructions of polity itself. Such an approach follows directly from the social constructionist positions on citizenship articulated by Shotter (1993) and Haste (2004).

Furthermore, the distinction between the political, civil and social domains allows for a focus on how social actors understand, define and enact rights and responsibilities across various interconnected spheres of activity, including political participation (political citizenship), protest and the use of public space (civil citizenship) and the welfare system and public services (social citizenship). The burgeoning literature on the social psychology of citizenship can be characterised as having begun to address several of these areas. For example, some work has been concerned with voting and other forms of political participation (e.g. Botindari \& Reicher, 2015; Condor \& Gibson, 2007; Gibson \& Hamilton, 2013; Riley, Morey \& Griffin, 2010); other work has addressed the use of public space (e.g. Blackwood, Hopkins \& Reicher, 2015; Di Masso, 2012, 2015; Dixon, Levine \& McCauley, 2006); and an overarching concern with the broader issue of polity membership can be identified in work concerned with issues around identity, belonging and intergroup relations (e.g. Abell, Stevenson \& Condor, 2006; Andreouli \& Howarth, 2013; Figgou, 2015; Gibson, 2015; Gibson \& Hamilton, 2011; Gray \& Griffin, 2014; Hopkins \& Blackwood, 2011). Clearly these distinctions are best thought of as heuristics rather than absolutes, with areas of overlap across the studies cited above (e.g. the use of public space in protest is a form of political participation). However, what this does highlight is that whereas there is a 
developing psychological literature on political and civil rights and responsibilities, as well as on conceptions of polity membership more broadly, there is as yet relatively little work exploring social citizenship. It is this which forms the focus of the present study.

\section{Social Citizenship}

In the UK, as in many liberal democracies during the $20^{\text {th }}$ century, and particularly since the end of the Second World War, it is the welfare state which has been the vehicle through which social rights and responsibilities have been translated into policy (Dwyer, 2000). The responsibilities of a contributory welfare system - that people pay taxes to fund welfare for those who have fallen on hard times - have long been enshrined in the welfare state (Rees, 1995). However, in recent years - since the advent of Thatcherism, and accelerated under the 'Third Way' (Giddens, 1998) approach of the New Labour governments of 1997-2010 - the responsibilities associated with social rights have increasingly been emphasised in such a way as to foreground the governance of individual conduct and subjectivity. This process of 'responsibilization' (Clarke, 2005) has led to rights to receive welfare payments and other social benefits (e.g. social housing) increasingly being made contingent on individuals demonstrating that they have met certain responsibilities concerning efforts to secure employment (Dwyer, 2004; Lund, 1999). Indeed, Lister (2002, p. 127) argued that, under New Labour, paid employment had become the 'supreme citizenship responsibility'. As argued by Rose (2000, p. 1407), in this context '[c]itizenship becomes contingent on conduct':

The excluded are characterized as failures, lacking personal skills and competencies. In the Third Way, these are to be addressed through practices of control targeted at the excluded themselves - principally those that seek to foster or coerce the development 
of the personal capacities thought to enable access to the workplace through the labor contract (Rose, 2000, p. 1406)

This process has continued under the Conservative-Liberal Democrat coalition government of 2010-15 (Taylor-Gooby, 2012; Dwyer \& Wright, 2014) and the Conservative majority government elected in 2015. For example, in October 2015 the then Secretary of State for Work and Pensions, Iain Duncan Smith, defended the government's approach against accusations that its plans for the welfare system are 'excessively punitive and bureaucratic' (Wintour, 2015). In doing so, Duncan Smith sought to argue that giving people a two week warning if their welfare payments are to be reduced for failing to meet their responsibilities ensures that 'claimants will have another opportunity to provide further evidence to explain their non-compliance', and that 'this will strike the right balance between claimant commitment and fairness' (Duncan Smith, cited in Wintour, 2015). Terms such as 'non-compliance' and 'claimant commitment' provide stark examples of the extent to which individual behaviour (non-compliance) and subjective processes (commitment) have become part of the standard policy language of welfare.

In this context, Stenner and Taylor (2008) have argued that a new 'psychosocial' approach is necessary to fully integrate the psychological and social dimensions of welfare. Indeed, they trace the neglect of welfare in the discipline of psychology to the separation between psychology and sociology as academic disciplines formed in the late nineteenth and early twentieth centuries, with the former focussing on individual and interpersonal processes, and the latter on social systems and institutional processes. As a result, 'psychology has not been concerned with welfare as a social project, but with the well-being of the hypothetically asocial individual' (Stenner \& Taylor, 2008, p. 417, italics in original). Indeed, this is arguably behind the absence of concern with citizenship more broadly from 
social psychology in the latter part of the twentieth century. As Laredo-Narciandi and Castro-Tejerina (2013) have demonstrated, citizenship was a concern in some early variants of social psychology, but this waned as the discipline came to be characterized by an experimental and hypothetico-deductive impetus as it sought to model itself increasingly on the natural sciences in the decades after the Second World War (Stevenson et al., 2015).

The small amount of social psychological work that has explored welfare and social citizenship suggests that the conditionality and psychologization of welfare evident at the policy level has been incorporated into the available repertoires of everyday commonsense. For example, Gibson (2009) highlighted how a repertoire of 'effortfulness' (characterized by terms such as laziness, effort, idleness) was used in online discussion forum comments concerning government plans for welfare reform. However, it was not simply the case that commenters held individuals responsible for their own employment status; it was also the case that the government itself was oriented to as a legitimate means for the policing of individual conduct through the way in which the welfare system was administered. Thus not only were individuals held to account for their conduct, but political-institutional actors were held to account for perceived failures to hold individuals to account. This challenges any straightforward distinction between individual and social explanations for unemployment, as apparent, for example, in an earlier tradition of work on lay explanations of unemployment which drew on mainstream attribution theories (e.g. Furnham, 1982).

Gibson (2011) extended this in an interview study of adolescents' talk concerning un/employment, showing how direct questions around such issues frequently resulted in the use of primarily individualistic explanations based around effort and hard work. However, when discussing a different topic - immigration - the same participants could treat unemployment in primarily socio-economic terms as being beyond the control of individuals, who were instead the passive victims of large-scale social processes (e.g. the stereotypical 
'immigrants taking our jobs' argument). Again, this challenges any straightforward attitudinal or attributional distinction between people who conceive of unemployment in an individualistic way and those who see it in terms of social factors. Rather, different explanations may be drawn on for different purposes in different contexts. Such findings point towards the dilemmatic nature of ideology surrounding welfare and social citizenship (Billig, Condor, Gane, Middleton \& Radley, 1988), and this approach was also taken by Andreouli and Dashtipour (2014) in their analysis of interviews with 'citizenship officers' (officials responsible for conducting citizenship ceremonies for people granted citizenship) in the UK. Andreouli and Dashtipour highlight how their participants could draw on the idea of 'earned citizenship' in order to resolve dilemmas between inclusion and exclusion, with immigrants welcomed provided that they could demonstrate a commitment to, and willingness to contribute to, their new country. In this respect, the figure of the immigrant as welfare-claimant was mobilised by some of the citizenship officers as an illustration of something that would not constitute 'earned citizenship'.

In the present study, we seek to build on these previous social psychological analyses of social citizenship, and in common with Gibson (2011) and Andreouli and Dashtipour (2014) our concern is with the way in which welfare could become a 'live' issue when matters of immigration were the explicit focus of debate. In this regard, our analysis concentrates on the ways in which social citizenship becomes bound up with debates concerning legitimate polity membership. The specific issue on which we focus is a recent context in which matters of polity membership have become relevant in the UK: namely, the movement of people within the European Union (EU). 


\section{The EU, Freedom of Movement, and the Social Charter}

Marshall (1950/1992) noted that his conception of citizenship was primarily a national citizenship. However, the 'nation-state' is far from the only polity to which an individual may be said to have a relationship of citizenship with ${ }^{\mathrm{i}}$. At the time of writing (July 2016), the UK is still a member of the EU, but has voted to leave following the referendum of $23^{\text {rd }}$ June 2016. The EU - as a supra-national polity - confers certain rights on citizens of its member states. For example, citizens of member states have the right to freedom of movement within the EU, although as Carrera (2005) has noted this has never been an unproblematic entitlement, with a range of barriers and obstacles standing in the way of the full extension of this right. One such limitation has been the imposition of controls regarding the extension of freedom of movement to citizens of new member states at the point at which they join the EU. For example, when Bulgaria and Romania acceded to the EU in 2007, several member states implemented restrictions on the rights of citizens of these countries to work. A similar situation obtains in respect of social citizenship at the level of the EU legal framework. The EU's mechanism for enshrining social and economic rights for citizens of member states is the European Social Charter (see Council of Europe, n.d.). The UK was a signatory to the original 1961 charter, and of the revised charter of 1996, but has not ratified the latter (Council of Europe, 2015), and also has an 'opt-out' of certain aspects of the charter negotiated in 2007 (European Union, 2007). As one legal commentator has noted, this has led to a situation in which the status of the applicability of the charter to the UK is 'mired in confusion and political prejudice' (English, 2011), although the Council of Europe (2015) provides a helpful summary document listing areas of compliance, partial compliance and non-compliance with the charter. It is not necessary for present purposes to go into full details of these, but two examples of reasons why the UK does not accord with the rights enshrined in the charter are that 'The level of Statutory Sick Pay, the Short Term Incapacity 
benefit and the Contributory Jobseekers Benefit for a single person are inadequate' and that 'Foreign workers who lose their jobs must leave the country, without the possibility of searching for new employment' (Council of Europe, 2015, p. 3, capitalization and punctuation as in original).

Given this complex legal situation, it is perhaps not surprising that these issues have often been the subject of heated political and media debate. Issues surrounding the rights and responsibilities of non-UK EU citizens in the UK, and the ability of the UK government to act unilaterally in respect of these rights and responsibilities, have recently been mobilized by the populist right-wing United Kingdom Independence Party (UKIP), which secured the largest share of the UK vote at the 2014 European Elections (27.5\%; 'UK European election results', 2014), and followed this up with its strongest ever showing at a UK General Election in May 2015, at which it achieved 3.88 million votes (a 12.6\% share; 'Election 2015 results'. 2015). These successes have been fuelled by linking its longtime ambition to withdraw the UK from the EU to popular concerns about immigration (Ford \& Goodwin, 2014), a strategy that pushed David Cameron to make a commitment to holding a referendum on EU membership, and ultimately to the referendum resulting in a vote to leave the EU. The dynamics of the referendum await fuller analysis, but it seems clear that immigration was a major issue in the debates that took place in the weeks and months leading up to it, and that UKIP's objective of getting EU migration onto the mainstream agenda of UK politics played an important part in the ultimate outcome of the referendum.

In this context, the present paper focuses on one recent manifestation of these debates surrounding EU immigration to the UK and social citizenship. Following the accession of Bulgaria and Romania to the EU in 2007, the UK government imposed restrictions on the rights of Bulgarian and Romanian citizens to work in the UK. These restrictions expired on $1^{\text {st }}$ January 2014, and the period leading up to this date was marked by something of a 
ratcheting up of anti-migration sentiment in the mainstream British press (Vicol \& Allen, 2014). In the present analysis, we explore one aspect of the public reaction to this by analysing data from an internet discussion forum hosted by a mainstream media outlet. In analysing these data we seek to address two related research questions: 1 . How is un/employment and welfare made relevant in the forum discussions?; 2. How are particular groups/categories (e.g. 'immigrants') constructed in relation to matters of un/employment and welfare?

\section{Method}

\section{Data}

The data are drawn from a discussion forum on the website of the British Broadcasting Corporation (BBC). The forum invited users to comment on the issue of immigration in response to an article entitled 'Viewpoints: How might Romanian and Bulgarian immigration affect the UK?' (“Viewpoints", 2013), published on $16^{\text {th }}$ August 2013. The article began by reporting a $26 \%$ increase in the number of Bulgarians and Romanians working in the UK over the period from April-June 2013, compared with the preceding three month period, before noting that the restrictions on citizens of these countries working in the UK were about to be removed. The main part of the article is then taken up by statements from five commentators (an economist, three think tank/pressure group representatives, and Nigel Farage, the then-leader of UKIP) concerning the likely impact of immigration from Bulgaria and Romania on the UK.

The discussion forum which follows this article consists of 635 comments, 597 of which were available for analysis as 38 had been removed by the forum moderators. The site lists several reasons why posts may be removed, including the posting of offensive or abusive comments, anything that breaks UK law, advertises a product, is off-topic, or contains 
personal information ('House rules', n.d.). In analysing these data we are not suggesting that they are representative of people's 'attitudes' or 'experiences', and nor are we suggesting that the comments represent the way in which the individuals who posted them would articulate themselves if these issues were discussed in another context (e.g. a research interview, a casual conversation with friends or co-workers). Rather, we treat the discursive genre of posts to an Internet discussion forum as worthy of study in its own right (Giles, 2016). The Internet is, of course, a hugely important aspect of contemporary social life. However, as it is still a fairly recent development, the way in which people engage with it remains relatively understudied by qualitative psychologists, for whom interviews remain the default method of data collection. However, online data are not only easier and more cost-effective to collect (Jowett, 2015), but they arguably have significant methodological advantages over the use of interviews and other forms of data that depend on direct researcher involvement, such as focus groups (Potter \& Hepburn, 2005). Specifically, data derived from discussion forums feature examples of argumentation and contestation that are provided for a purpose other than merely for the benefit of a social science interviewer. This is not to deny the usefulness of interviews, but rather to assert that online data - and discussion forum data specifically have some important features to recommend them.

However, critiques of interview research have tended towards a prioritization of the immediate interactional context over the sedimented cultural themes of history and ideology. In much the same way as Wetherell (2003, p. 13) theorises interview data as 'a highly specific social production, ... [but one that] also draws on routine and highly consensual (cultural/normative) resources that carry beyond the immediate local context, connecting local talk with discursive history', so we would argue that all discourse - including the online forum data studied here - needs to be analysed not simply with a view to moment-by- 
moment construction, but with an attention to the broader cultural patterns manifested in discourse.

\section{Analytic perspective and procedure}

Our analysis was informed by the principles and techniques of discourse analysis (Potter \& Wetherell, 1987), discursive psychology (Edwards \& Potter, 1992) and rhetorical psychology (Billig, 1996). Though we do not wish to underplay the distinctions between different approaches, for present purposes we refer to our analytic approach as discursiverhetorical psychology. Briefly, this approach is underpinned by a social constructionist epistemology which emphasises that rather than making inferences concerning the relationship between any description and a separate realm of reality, analysts should instead explore the ways in which reality itself is constructed through discourse. Allied to this focus on construction is a concern for function, such that discourse is theorised as being inherently oriented towards the performance of actions, such as blaming, denying, identifying, inviting, refusing, and so on. In exploring how particular constructions are worked up to perform specific functions, discursive-rhetorical psychologists also attend to the situated nature of discourse, that is the way in which language is tied to the context if its articulation. Finally, the specifically rhetorical nature of discourse is emphasised in a focus on how particular constructions are always worked up in opposition to potential alternative constructions (even if these are unstated), and thus a pervasive function of discourse is to buttress claims and to persuade recipients. Jowett (2015) and Rowe and Burke (2015) have recently highlighted the virtues of such approaches for exploring online data, and indeed a number of studies have applied this approach to the study of websites, blogs, discussion forums and social media posts, with a growing literature on exclusionary discourse based around 'race', immigration 
and related issues (e.g. Billig, 2001; Burke \& Goodman, 2012; Durrheim, Greener \& Whitehead, 2015; Goodman \& Rowe, 2014; Wood \& Finlay, 2008; Sakki \& Petterson, 2015).

Our analysis began with repeated reading of the data in order to identify potential avenues for fuller exploration. A process of coding was then undertaken to identify comments in which various issues were raised, or forms of argument used. This process, conducted initially by the second and third authors, and then independently by the first author, followed Potter and Wetherell's (1987) guidelines for coding, with the aim being 'to squeeze an unwieldy body of discourse into manageable chunks' (p. 167). This involved further reading of the data and manual note-taking, leading to the creation of several Microsoft Word documents in which thematically similar comments were collated (e.g. all those in which immigrants were constructed as potential welfare claimants; all those in which immigrants were glossed as hard-working; etc.). Once we had these documents, the analysis proper began, with the concept of interpretative repertoire (Potter \& Wetherell, 1987; Wetherell \& Potter, 1988) being particularly useful, as was Billig's (1996) focus on rhetorical strategies. Our analysis was thus concerned with identifying the 'recurrently used systems of terms used for characterizing and evaluating' (Potter \& Wetherell, 1987, p. 149) immigrants and immigration, as well as the way in which these were used to advance particular arguments (e.g. pro- or anti-immigration). This involved a systematic process of noting where particular interpretative repertoires were used in the data, and how they were invoked for the advancement of particular lines or argument (e.g. for or against immigration). However, following Potter and Wetherell (1987), we did not identify a particular level of frequency as defining the importance or prevalence of an interpretative repertoire, but rather we approached this more as a matter of traditional scholarship (Billig, 1988a), in which implicit references can qualify as examples just as much as explicit ones, provided that they can be shown to be doing so. The key issue here is that the analysis is presented in such a 
way as to make examples available for inspection by readers, and in common with the vast majority of research in the discursive-rhetorical tradition we provide numerous extracts in the analytic section below. Micro-analysis of individual comments was informed by the principles of discursive psychology (Edwards \& Potter, 1992), with a focus on the discursive devices used to construct particular images of, and arguments concerning, immigrants and immigration. Again, there is no hard-and-fast set of rules to put into practice for the identification of such devices, but rather their identification depends upon the analyst's familiarity with, and immersion in, the relevant literature. It is in this respect that Potter and Wetherell (1987, p. 168) assert that '[a]nalysis of discourse is like riding a bicycle compared to conducting experiments or analysing survey data which resemble baking cakes from a recipe.'

\section{Analysis}

In straightforward terms, $371(62 \%)$ posts featured arguments that were broadly or wholly negative about migration, $100(17 \%)$ featured arguments that were broadly or wholly positive about migration, with a further $126(21 \%)$ posts featuring arguments that were broadly neutral, or where a clear evaluative position was not clear. These figures are presented in order to orient readers to the general patterning of arguments for and against migration across the dataset, and not in an attempt to suggest that the data are in any way reflective of popular views more broadly. Indeed, the nature of online data necessitates caution about attributing posts to particular individuals. Counting the number of posts in the positive and negative camps does not take account of the extent to which some people posted multiple comments from the same username. It might be suggested that counting the number of posters (rather than posts) articulating positive and negative arguments might provide a solution to this, but such a strategy would not take into account the fact that it is perfectly 
possible for the same individual to operate multiple accounts with different usernames (i.e. to give the appearance that more people are saying similar things). Indeed, such possibilities are oriented to by some posters themselves, and this points to an alternative approach which is to treat such matters not as a methodological problem for the analyst to solve, but as a members' concern that can be made live in specific contexts in order to challenge positions that are being glossed as consensual (i.e. by suggesting that the apparent consensus is artificially manufactured [see Gibson, forthcoming]).

The focus of the present analysis is therefore on the way in which the arguments presented in the comments are put together, and the images of particular groups that are presented. Moreover, the specific concern of the present analysis is with invocations of matters relating to what might be termed an interpretative repertoire of social citizenship: rights and responsibilities relating to (un)employment, welfare and public services. In this respect, the present analysis focuses on two key findings: First, the use of (un)employment, welfare and public services in arguments against immigration will be explored. Here, we will also draw attention to the ways in which posters inoculate themselves against accusations of prejudice. Second, the use of an interpretative repertoire of effortfulness in pro-immigration arguments will be explored. An over-arching concern of the analysis is with the construction of particular groups (e.g. 'immigrants', 'Eastern Europeans', 'white working class Brits') in ways which render some consequence or course of action necessary. Again, it is important to recognise that dealing with these issues brings with it self-presentational concerns for posters, and in common with a wide array of literature on discourse, immigration, 'race' and related matters (for reviews, see Every \& Augoustinos, 2007; Goodman, 2014), we also attend to the way in which speakers engage in impression management work in order to present themselves as rational and non-prejudiced. 


\section{Invocations of Unemployment, Welfare and Public Services in Arguments against Migration}

The themes of social citizenship - un/employment, welfare and public services could be readily identified in posters' arguments against migration. As rhetorical strategies these drew on the implicit social contract (which was sometimes made explicit) at the heart of the welfare state, as well as assuming that citizens of the UK should have rights to employment within the UK that should not be extended to non-UK citizens. We will explore each of these three issues in turn, with a focus on how the arguments were constructed as being rational, factual and non-prejudiced.

Migration as a cause of unemployment. A persistent argument used in the dataset involved the suggestion that immigration would lead to unemployment amongst UK nationals. Such arguments could involve either direct or more banal invocations of identity

\section{Comment 1}

We don't need them and we don't want them. British job vacancies need to be filled by British Citizens first and foremost, irrespective of what the eu say. This is OUR country and we should make the rules NOT the Brussels mafia !

\section{Comment 2}

if all the migrants left would there be any uk unemployment? and would wages and conditions be so bad? Whoever benefits from low paid agency labour its not the unemployed is it?

In comment 1 , the poster explicitly argues for the prioritization of 'British Citizens' in the job market, setting a clear distinction between $u$ s and them ('We don't need them and we don't want them.'). This is followed by explicit criticism of the EU, whose legitimacy is 
undermined through the use of the term 'Brussels mafia', with the assertion that 'we' should 'make the rules'. The poster's capitalization in 'OUR county' further serves to underline this fairly straightforward link between identity and employment rights.

By way of contrast, in comment 2 the poster adopts a more implicit framing. There are no assertions of 'British' (or any other) identity and no clear distinctions between 'us' and 'them'. However, more subtle deictical referents are used here, with the contrast between 'the migrants' and 'the unemployed' relying on the bridging assumption that 'the migrants' are not part of the 'the unemployed', and that 'uk unemployment' does not include 'the migrants', but rather that they are a cause of it (as well as of low wages and poor conditions).

In addition to straightforward assertions that immigration was likely to lead to unemployment for UK nationals, many posts referred to the specific type of migrant labor that would be likely to arrive as a result of Bulgarian and Romanian immigration, with migrants frequently constructed as being 'low-skilled'. This could be used to argue that migrant labor would be likely to lead to unemployment particularly amongst poorer and lower-skilled UK nationals, or as in the following example to suggest that the "economic potential' of the UK would be adversely affected:

\section{Comment 3}

For whatever reason, diet culture or whatever, the IQ of Romanians is somewhat lower than the UK and we are inviting the least skilled in who are likely to be least bright crayons in a somewhat dim box. What is this going ot mean if they settle except a lowering of economic potential as meaningful activity is replaced by the idiot stomp?

The commenter explicitly glosses Romanians as having lower IQ scores than the UK population, and suggests that those who come to the UK are likely to be those who are 'least 
skilled' and least intelligent ('least bright crayons in a somewhat dim box'). This example is somewhat atypical insofar as it involves an explicit reference to intelligence, but nevertheless the commenter can be seen to be avoiding constructing group difference in crudely biological terms, prefacing the claim about IQ with references to the possibility that these differences may be caused by diet or culture. However, it is also notable that the phrase 'For whatever reason', coupled with the generalised list completer (Jefferson, 1990) 'or whatever' functions as a form of strategic vagueness (Edwards \& Potter, 1992) which allows for the plausibility of other (non-cultural) explanations. This is a good example of how even highly unfavourable constructions of outgroups could be oriented towards 'dodging the identity of prejudice' (Wetherell \& Potter, 1992, p. 211). The implication of biological inferiority is left unstated, with the trope of cultural difference instead doing the work of providing an overt account for group differences (Durrheim \& Dixon, 2000).

Public services. Posters argued that population increases caused by immigration would put unbearable pressure on public services, in particular healthcare, education and housing. For example:

\section{Comment 4}

it's nearly funny,our little islands coast is eroding away yet we keep on letting the population explode with immigrants \& their offspring.Putting strain on our ancient infrastructure, with no money to improve.,Teachers tryin to overcome multiple language barriers with standards dropping,shortage in housing \& hospital beds,importing food \& energy to meet extra demand,a water \& sewage system failing

The poster's use of geographical imagery functions as a container metaphor (Charteris-Black, 2006) insofar as it implies that the UK has finite space, with the added piquancy of coastal 
erosion being used to suggest that not only is 'our little island' small, but that it is getting smaller. Furthermore, this use of the geographical enables the poster to argue against immigration without appearing to be biased against any particular group of people (Abell, Condor \& Stevenson, 2006), thus neatly anticipating, and inoculating against, the possibility of being accused of prejudice (Billig, 1988b). Extreme case formulation (ECF; Pomerantz, 1986) is subsequently used to work up the folly of continued immigration ("we keep on letting the population explode'). Furthermore, the poster constructs public services as already problematic ('our ancient infrastructure') and thus as being unable to cope with additional 'strain' in the face of 'extra demand'.

Immigrants as welfare claimants. Arguments that constructed immigrants as attracted to the UK in order to receive social welfare benefits drew on the contributory nature of the welfare system:

\section{Comment 5}

I think our government needs to ensure that only people that have 'paid into the pot' can claim benefits, and set the system so that people not born in the uk only get benefits at the levels offered in their own country. This would stop benefits tourism.

In this example, the commenter uses the phrase 'benefits tourism', a term which appears to be reaching the status of rhetorical commonplace or cliché, and which refers to a process whereby people come to the UK simply in order to take advantage of the welfare system. It is notable that the commenter does not need to explain what is meant by 'benefits tourism', or to provide an argument that this process actually occurs. Rather, it is simply assumed that it is a problem that readers will recognise, and to which a solution should be offered. In this sense, the term can be understood as an example of common knowledge (Edwards \& Mercer, 1987) - something that can be invoked with the assumption that recipients will understand 
what is meant. The commenter explicitly suggests country of birth as a criterion for entitlements to receive welfare benefits, as well as arguing that only those who have paid UK tax (indicated by the colloquialism 'paid into the pot') are entitled to receive benefits. Such arguments assume that (a) no one born outside the UK is a British citizen; (b) no one born outside the UK has paid UK tax; and (c) that all UK citizens have 'paid into the pot'.

In some cases, welfare was invoked in distinctions between desirable and undesirable immigrants. For example:

\section{Comment 6}

Why can't we have a points based system for immigration? Then we can separate those who will add value from the scroungers who come here for free healthcare and benefits.

The commenter constructs a distinction between two types of immigrants: 'those who will add value' and 'scroungers'. This echoes previous studies of the discursive construction of marginalized and minority groups (e.g. Gibson, 2011; Lynn \& Lea, 2003) which have highlighted how speakers/writers can make an apparent concession by distinguishing between 'good' and 'bad' outgroup members to demonstrate that they are not opposed in principle to some group or other being afforded certain entitlements, but that the group needs to be monitored closely. This is useful strategy for 'dodging the identity of prejudice' (Wetherell \& Potter, 1992, p. 211) insofar as it allows the poster to positon themselves as not being opposed to any specific group on national, ethnic or religious grounds (Augoustinos \& Every, 2007). In this case, this special monitoring takes the form of 'a points based system'. Such a system is advocated most vociferously in the UK by UKIP (e.g. UKIP, 2015). For those arguing for limits on immigration, it has the advantage of enabling them (a) to avoid the implication that they are anti-immigration tout court; and (b) to frame their decisions about 
who should and shouldn't be allowed to live in the UK as being based purely on individual factors, rather than on the basis of group identity (Gibson \& Booth, forthcoming).

In contrast, other posters avoided making an explicit distinction between different categories of immigrants, and instead made a distinction between the entitlement to work and the entitlement to welfare. For example, the following commenter explicitly rejects criticisms based around the effects of immigration on the UK employment market, but suggests that rights to work should not be accompanied by entitlements to welfare:

\section{Comment 7}

I worked in Bulgaria for 8 years. What is the problem if they are working here. It is when they are claiming benefits is the problem.

In stating that s/he has worked in Bulgaria, the poster claims first-hand experience relevant to the issue under discussion. Specifically, the poster positions themselves as someone who has taken advantage of the opportunity to seek employment elsewhere in the EU. The subsequent assertion 'What is the problem if they are working here?' can thus be seen as a form of quid pro quo - I worked in Bulgaria, so it is only fair that 'they' can work 'here'. This enables the poster to position her/himself as not dispositionally-inclined to be anti-immigrant, and thus avoid the implication that they may be prejudiced, but rather to oppose only those immigrants who claim welfare benefits. It is also notable that, in contrast with comment 6 , this poster does not imply that welfare benefits are themselves a motive for coming to the UK, simply that claiming them is 'the problem'. Again, however, this takes for granted 'their' nonentitlement to draw on the UK welfare system. 


\section{Invocations of Effortfulness in Pro-Immigration Arguments}

While the majority of comments on the discussion forum outlined arguments against immigration, as noted above there was a sizeable minority in which anti-immigration arguments were challenged, or in which explicitly pro-immigration arguments were outlined. Issues of employment and welfare were frequently mobilized in such comments, with the interpretative repertoire of effortfulness (Gibson, 2009) particularly notable.

Immigrants as hard workers. Posters challenging anti-immigration arguments often attributed traits such as 'hard working' to migrant groups. For example, in the following post the commenter counters the argument that immigrants are likely to be low-skilled:

\section{Comment 8}

Many romanians are well qualified. The rates of pay in Romania are seriously low compared to UK and many Romanians will earn more in even the uk's lowest paid jobs than they can in Romania. Most Romanians in Romania work much longer hours then we are acostomed to in the UK They will do low paid jobs here very well, and given time, move up employment ladder.

The contrast between wages in Romania and the UK is worked up through the use of ECF ('seriously low'; 'even the uk's lowest paid jobs'). Furthermore, Romanians are constructed as being 'accustomed' to 'much longer hours'. Rather than leaving the impression that wellqualified Romanians will languish in poorly-paid jobs in the UK, the commenter draws on the commonplace metaphor of the 'employment ladder' to suggest that through their willingness to work hard, Romanians will be able to secure higher-status employment in due course. In this example, we see a relatively implicit intergroup comparison worked up between 'Romanians' and 'we in the UK', with the suggestion that 'we' are accustomed to 
shorter working hours. In several posts, however, intergroup comparisons were made more explicit.

Constructing the 'lazy' British. Arguments in favour of immigration frequently involved the continued reliance on the construction of group differences, with a sub-group of British citizens being treated as morally and/or psychologically deficient in comparison to hard-working immigrants. In some cases this could take a relatively subtle form, with the welfare system itself being criticised through the construction of a lay version of the 'dependency culture' argument (Dean \& Taylor-Gooby, 1992):

\section{Comment 9}

why are eastern europeans willing to come here? because there are jobs.

why are there jobs for eastern europeans while there doesn't seem to be british jobs for british workers? because british workers would rather get generous british benefits than work and pay stupid british tax (which is high in order to pay the benefits) so. lower benefits. more incentive to go out and work. less tax to pay

This poster uses a question-and-answer format in order to assert that jobs are readily available, but that 'british workers' do not take them because of the 'generous' welfare system that leads them to prefer benefits to employment. While the problem is clearly identified as the welfare system itself, the poster subtly contrasts 'eastern europeans' with 'british workers' insofar as the former seek jobs, whereas the latter 'would rather' not given the current welfare system. Thus, while the welfare system is constructed as creating incentives to either take paid employment or not, the poster treats these incentives as only applying to one group: 'british workers' need to be incentivised in a way that 'eastern europeans' seemingly do not. 
In contrast, some posters drew explicitly on a repertoire of effortfulness to construct a generic category of British people who were not displaying desirable characteristics and/or behaviours in relation to employment:

\section{Comment 10}

Don't worry about the Romanians and Bulgarians. Worry about the many home grown workshy and benefit scroungers, and the morally bankrupt and degenrate (employed and unemployed) who are dragging this so-called great country downwards.

This poster dismisses concerns that Romanian and Bulgarian immigration is anything to 'worry' about, but does so by constructing an image of a morally-deficient category of 'home grown' people who are 'dragging this so-called great country downwards'. This comment is instructive for several reasons. First, it highlights the point that comments that dismissed the concerns of those arguing against immigration could just as readily contain evidence of stereotyping and outgroup derogation. The framing of the issue was, however, changed in such circumstances, with the explicitly national intergroup framing replaced by a distinction between different categories of 'home grown' or 'British' people. Again, this mirrors the distinction between 'good' and 'bad' migrants noted above, and in previous research (e.g. Augoustinos \& Every, 2007). Second, the minimization of the national intergroup framework is accompanied by an argument that is explicitly oriented towards demonstrating concern for 'this so-called great country'. Indeed, the narrative of national decline (Condor, 1996, 2006) that the poster works up involves a fairly straightforward lament at the various 'morally bankrupt' members of the ingroup who are held to be responsible for this decline. The impression is certainly not that categories of nation/state are irrelevant, but rather that the poster is deeply troubled by this decline, and that s/he holds ingroup members rather than outgroup members responsible. 
Sometimes the accusation of laziness was levelled specifically against those who were heard to be complaining about immigration:

\section{Comment 11}

Get over it folks... for hundreds if not thousands of years people have been coming to Britain to work and our people have done the same. Many of the jobs that will be taken will be ones that many Brits believe are beneath them anyway and those complaining the loudest will often be those too lazy to go out and find work themselves. Anybody who works and pays tax is welcome in my eyes!

Again, the comment opens with a retort to those who argue that immigration is a problem, and the poster constructs the current situation as simply a continuation of an extended (and therefore normal, unremarkable) historical process. The poster not only characterizes British complainants as likely to be 'lazy', but also introduces a further trope which was apparent across several comments concerning the extent to which the jobs that will be filled by immigrants are likely to be those that 'many Brits believe are beneath them'. Not only are the complainants morally accountable for their laziness, they are thus also positioned as being arrogant. The final sentence, 'Anybody who works and pays tax is welcome in my eyes!' makes explicit the underlying premise of this and similar posts, which is that paid employment and payment of taxes are elevated to being the primary citizenship responsibility, even to the point where it takes precedence over 'national' group membership. This has the advantage of enabling posters to present themselves as non-prejudiced (i.e. because they dismiss the importance of explicitly group-based criteria) whilst working up a distinction between those who display the desirable psychological characteristics of good citizens (i.e. effortfulness, a lack of fussiness about the type of work that they do) and those who are morally deficient (i.e. lazy, arrogant, etc.) 
In some cases, posters went further than this and introduced an alternative intergroup framework based explicitly around class. For example, consider the following comment, which is framed as a direct response to a previous poster ('79') who had invoked high youth unemployment as a reason why immigration was problematic:

\section{Comment 12}

79.

Whi is youth unemployment so high? I work in an inner city school, and the kids who give us the most grief are white working class Brits - or should I rather say unemployment class? Often nobody in the family has done an honest day's work for generations. They are unemployable.

Exam results at our school are up - thanks to the Eastern Europeans who are interested in education.

The comment involves constructing an explanation for why unemployment is 'so high', and this explanation rests on an argument from experience ('I work in an inner city school...'), which works to construct the account as factual and thus difficult to contest (Pomerantz, 1984; Potter, 1996). The poster frames the problem as revolving around 'white working class Brits', subsequently glossed as the 'unemployment class' in such a way as to make unemployment a category feature of this group. By working up a lay sociological theory of long-term generational unemployment the poster treats the problem as intractable and thus no solution is offered. Indeed, rather than treating this as a case of underinvestment and neglect of people in deprived areas, the poster ascribes certain negative characteristics to this group: they cause trouble for teachers ('give us the most grief') and they are inclined not to be 
honest ('nobody in the family has done an honest day's work'). Moreover, the 'Eastern Europeans' are credited with having improved exam results due to being 'interested in education'. The implication of this is that 'white working class Brits' are not 'interested in education' and are thus responsible for their own failings.

Given the minority status of pro-immigration arguments in the context of this discussion thread, it should come as no surprise that arguments such as these were seized on by those making anti-immigration arguments. To explore this, we will consider a response to a comment which includes a form of the argument that 'migrant workers' are likely to 'work harder' then the 'indigenous population'. First, we present the original comment:

\section{Comment 13}

Today I listened to a man running a building site saying that he liked migrant workers because they work harder and are more reliable than the indigenous population.

This comment is constructed in such a way as to inoculate the poster from accusations of bias or subjectivity. By framing the point about 'migrant workers' as having being heard coming from a third party in a position which would be expected to confer expertise on such matters ('a man running a building site'), the poster is able to externalise the intergroup comparison between 'migrant workers' and 'the indigenous population' (Potter, 1996). However, such rhetorical strategies were no guarantee of success. The interactive nature of Internet forums means that posters can respond to previous comments, and in this case the poster's rationality was called into question in a subsequent post:

\section{Comment 14}

\#193---what a very simplistic, naive and narrow point to post on a serious site !!! I heard a bloke the other day say that Hitler was much under-rated. So what do I do when I hear "a bloke" say something. I use my brain-----it's in the head and allows us 
to think for OURSELVES. Did the bloke you overheard hire immigrants at dirt-cheap prices that are cutting his costs? Go to a kiddies' Forum !!!!

This poster begins the process of ridiculing the previous comment through a combination of ECF (Pomerantz, 1986; 'very'), three-part list (Jefferson, 1990; 'simplistic, naive and narrow') and punctuation used to mark incredulity ('!!!’). The poster also works up a contrast between the poor quality of the previous post and the 'serious' nature of the discussion forum, and then builds an ironic analogy involving Hitler to accuse the previous poster of not thinking. This is followed by an attribution of stake and interest (Edwards \& Potter, 1992) to the 'bloke you overheard' - i.e. suggesting that he is likely to be seeking to cut costs - before the withering rebuke is completed with the suggestion that the previous poster is not only unable to think, but her/his arguments are immature and childlike ('Go to a kiddies' forum!!!'). It is palpably not the case, therefore, that constructions such as immigrants-as-hard-workers were not contested by the other posters on the forum. Just as those identifying the 'real problem' as 'lazy' 'white working class Brits' could exhort their opponents in argument to 'get over it', so those opponents could respond in kind. Debates over the movement of people, and their social citizenship rights and responsibilities, are thus inseparable from debates over who is to 'blame' for perceived problems and from competing constructions of a variety of groups (Romanians, Bulgarians, Eastern Europeans, working class Brits, etc.).

\section{Discussion}

The present analysis has explored invocations of welfare, un/employment and related issues in a discussion forum concerned with the potential effects of EU immigration on the UK. The findings point to the ways in which those advancing arguments against immigration 
could present it as likely to cause unemployment amongst UK nationals, likely to lead to increased pressure on public services and likely to attract people who wish to draw on the UK's welfare system. These arguments themselves demonstrate the flexibility to which ideological resources could be put, with some arguments assuming that Bulgarian and Romanian migrants are likely to be too economically active and thus deprive UK nationals of jobs, whereas other arguments constructed them as insufficiently economically active and thus liable to draw on the resources of the UK welfare state (see also Gibson, 2015). In contrast, arguments that challenged such anti-immigration perspectives could draw on a further stereotype - not of Romanians, Bulgarians, or eastern Europeans more broadly - but of a sub-group of British people, constructing them as failing to display the psychological characteristics necessary to secure employment, and thus as implicitly (or often explicitly) deserving of their fate.

These findings develop previous work in a number of ways. First, the finding that not only anti-immigration arguments featured the construction of outgroups in derogatory terms, but that challenges to such arguments could just as readily draw on images of a deficient and illegitimate 'other' who was deemed to be responsible for the UK's ills brings into question any suggestion that pro-immigration stances are by definition necessarily more progressive, liberal or enlightened than anti-immigration positions. In reality, such a claim is rarely made explicitly in the academic literature, but the error is more one of omission that of commission. Extant analyses of immigration discourse typically focus on anti-immigrant positions, in an attempt to deconstruct how exclusionary arguments are put together and (implicitly or explicitly) to provide a political challenge to such arguments. This has been and continues to be - an important project, but it is one that has yet to be accompanied by a turning of critical attention to pro-immigration arguments that treat immigration in purely economic terms, and/or which involve the implication that sections of the UK population are 
themselves 'characterized as failures, lacking personal skills and competencies' (Rose, 2000, p. 1406). In this respect, we might be well-advised to consider Reicher's (1997) concerns, which echo well-established arguments on the left against the project of European economic integration, that setting up a binary opposition between an enlightened, liberal, progressive pro-EU position, and a dangerous, xenophobic and nationalistic anti-EU position is an ideological accomplishment itself insofar as it obscures objections to European integration based around anti-capitalist arguments.

Second, and relatedly, the present findings highlight the importance of attempts to incorporate a concern for class into social psychological analyses of citizenship. Rather like citizenship, class has only rarely been an explicit concern of social psychologists, but there has been a recent revival of interest in the concept (Day, Rickett \& Woolhouse, 2014; Hodgetts \& Griffin, 2015). We would argue that there is the potential for research on citizenship and class to proceed alongside each other, and that the concept of social citizenship in particular will be an important focus of these growing areas of research. After all, Marshall's (1950/1992) classic outline of social citizenship was provided in a volume entitled 'Citizenship and Social Class' (emphasis added), and in the same way as we should theorise citizenship as bound up with categories of gender, ethnicity and nation, it is incumbent on social psychologists engaged in the study of citizenship not to lose sight of the infusion of rights and responsibilities with discourses of class. Indeed, Reicher's (1997, p. 84) position is again instructive: 'I do not conceptualize the EU in terms of nationality. Indeed, I consider the notion of national interest as an abstraction to cover the impact of particular economic policies on those in different economic positions - in crude terms, class.' Thus analysts should not treat nation as somehow pre-eminent or as necessarily the most relevant social category for citizenship (Condor, 2000), and nor should such a concern lead to the prioritizing of class over other social categories (e.g. ethnicity, gender) - something 
which would open social psychological work to the same critique of prioritizing class as befell classic Marxism. Rather, social psychologists, particularly those adopting qualitative approaches, are well-placed to treat the relevance of - and intersections between (Condor \& Fenton, 2012) - particular social categories as an empirical question.

Third, it is notable that arguments concerning social citizenship rights and responsibilities are inseparable from attempts to define groups, or to construct distinctions between different types of group members. Debates over membership are thus bound up with debates over rights (e.g. to claim welfare benefits) and responsibilities (e.g. to pay taxes); and positions on who has these rights and responsibilities are bound up with the construction of particular groups in particular ways (e.g. as lazy, or as hard working, etc.). In this respect, we are dealing not simply with abstract questions concerning rights and responsibilities in a context where it is clear who counts as a citizen, but rather the definition of 'competent membership in a polity' (Isin \& Wood, 1999, p. 4) is itself at stake. This highlights the extent to which qualitative psychological approaches can address an issue sometimes neglected in the literature on citizenship in the wider social sciences, where debates over membership and citizenship are often treated as a theoretical and/or policy level problem rather than as an empirical matter (see also Condor, 2011a).

Fourth, the specific approach adopted here - discursive-rhetorical psychology - has particular virtues for the analysis of social citizenship. As Stenner and Taylor (2008), Rose (2000) and others have argued, contemporary welfare regimes are bound up with assumptions concerning the psychological. In treating psychological terms (e.g. laziness, hardworking, etc.) as discursive devices invoked to do particular business in particular contexts, the discursive-rhetorical approach is well-placed to contribute to the critical project of analysing how such assumptions have been woven into contemporary common sense. Social policy analysts have identified how these assumptions have been enshrined in policy and other 
institutional discourse, but there is important work to be done in mapping the currents of everyday discourse.

The analysis presented in the present paper is but a small contribution to such an endeavour, and it should be emphasised that the present analysis has only explored data from one highly particular context, and as such our claims should not be seen as an attempt at empirical generalization. However, we would argue that these analyses (a) highlight the usefulness of analysing discursive constructions of welfare in relation to immigration; (b) point to the need for further social psychological explorations of social citizenship; and (c) draw attention to points of connection between social citizenship and other current social psychological concerns, such as group membership and intergroup relations, the norm against prejudice and the emerging concern with social class. Moreover, the analysis highlights the extent to which the psychological assumptions at the heart of recent attempts to re-shape the welfare system in the UK (and beyond) continue to exist in a dialectical relationship with popular discourse on the subject, with the repertoire of effortfulness constituting a cultural resource that can be deployed in order to manage claims concerning who is - and who is not - entitled to full citizenship status. 


\section{References}

Abell, J., Condor, S., \& Stevenson, C. (2006). "We are an island": Geographical imagery in accounts of citizenship, civil society, and national identity in Scotland and in England. Political Psychology, 27, 207-226. doi: 10.1111/j.1467-9221.2006.00003.x

Andreouli, E., \& Dashtipour, P. (2014). British citizenship and the 'other': An analysis of the earned citizenship discourse. Journal of Community \& Applied Social Psychology, 24, 100-110. doi: 10.1002/casp.2154

Andreouli, E., \& Howarth, C. (2013). National identity, citizenship and immigration: Putting identity in context. Journal for the Theory of Social Behaviour, 43, 361-382. doi: 10.1111/j.1468-5914.2012.00501.x

Augoustinos, M., \& Every, D. (2007). The language of 'race' and prejudice: A discourse of denial, reason, and liberal-practical politics. Journal of Language and Social Psychology, 26, 123-141. doi: 10.1177/0261927X07300075

Billig, M. (1988a). Methodology and scholarship in understanding ideological explanation. In C. Antaki (Ed.), Analysing everyday explanation: A casebook of methods (pp. 199. 215). London: Sage.

Billig, M. (1988b). The notion of 'prejudice': Some rhetorical and ideological aspects. Text, 8, 91-110. doi: 10.1515/text.1.1988.8.1-2.91

Billig, M. (1996). Arguing and thinking: A rhetorical approach to social psychology. Cambridge: Cambridge University Press.

Billig, M. (2001). Humour and hatred: The racist jokes of the Ku Klux Klan. Discourse \& Society, 12, 267-289. doi: 10.1177/0957926501012003001

Billig, M., Condor, S., Edwards, D., Gane, M., Middleton, D., \& Radley, A. (1988). Ideological dilemmas: A social psychology of everyday thinking. London: Sage. 
Blackwood, L., Hopkins, N., \& Reicher, S. D. (2015). 'Flying while Muslim': Citizenship and misrecognition in the airport. Journal of Social \& Political Psychology, 3, 148170. doi: $10.5964 /$ jspp.v3i2.375

Botindari, L., \& Reicher, S. D. (2015). The active follower: What young voters look for in political leaders and parties. Journal of Social \& Political Psychology, 3, 107-130. doi: $10.5964 /$ jspp.v3i2.413

Burke, S., \& Goodman, S. (2012). 'Bring back Hitler's gas chambers': Asylum seeking, Nazis and Facebook - a discursive analysis. Discourse \& Society, 23, 19-33. doi: $10.1177 / 0957926511431036$

Carrera, S. (2005). What does free movement mean in theory and practice in an enlarged EU? European Law Journal, 11, 699-721. doi: 10.1111/j.1468-0386.2005.00283.x

Charteris-Black, J. (2006). Britain as a container: Immigration metaphors in the 2005 election campaign. Discourse \& Society, 17, 563-581. doi: $10.1177 / 0957926506066345$

Clarke, J. (2005). New Labour's citizens: Activated, empowered, responsibilized, abandoned? Critical Social Policy, 25, 447-463. doi: 10.1177/0261018305057024

Colley, L. (1992). Britons: Forging the nation 1707-1837. New Haven, CT: Yale University Press.

Condor, S. (1996). Unimagined community? Some social psychological issues concerning English national identity. In G. Breakwell \& E. Lyons (Eds.), Changing European identities (pp. 41-68). London: Butterworth Heinemann.

Condor, S. (2000). Pride and prejudice: Identity management in English people's talk about 'this country'. Discourse \& Society, 11, 175-205. doi:

$10.1177 / 0957926500011002003$ 
Condor, S. (2006). Temporality and collectivity: Diversity, history and the rhetorical construction of national entitativity. British Journal of Social Psychology, 45, 657682. doi: $10.1348 / 014466605 \times 82341$

Condor, S. (2011a). Towards a social psychology of citizenship? Introduction to the special issue. Journal of Community \& Applied Social Psychology, 21, 193-201. doi: 10.1002/casp.1089

Condor, S. (2011b). Rebranding Britain? Ideological dilemmas in political appeals to 'British multiculturalism'. In M. Barrett, C. Flood \& J. Eade (Eds.), Nationalism, ethnicity, citizenship: Multidisciplinaryperspectives (pp.101-134). Newcastle upon Tyne: Cambridge Scholars.

Condor, S., \& Fenton, S. (2012). Thinking across domains: Class, nation and racism in England and Britain. Ethnicities, 12, 385-393. doi: 10.1177/1468796812448016

Condor, S., \& Gibson, S. (2007). 'Everybody's entitled to their own opinion': Ideological dilemmas of liberal individualism and active citizenship. Journal of Community \& Applied Social Psychology, 17, 115-140. doi: 10.1002/casp.885

Council of Europe. (n.d.). European social charter. Retrieved from http://www.coe.int/T/DGHL/Monitoring/SocialCharter/

Council of Europe. (2015). The United Kingdom and the European social charter. Retrieved from http://www.coe.int/t/dghl/monitoring/socialcharter/CountryFactsheets/UK_en.pdf

Day, K., Rickett, B., \& Woolhouse, M. (2014). Class dismissed: Putting social class on the critical psychological agenda. Social \& Personality Psychology Compass, 8, 397407. doi: $10.1111 / \mathrm{spc} 3.12118$

Dean, H., \& Taylor-Gooby, P. (1992). Dependency culture: The explosion of a myth. Hemel Hempstead: Harvester Wheatsheaf. 
Di Masso, A. (2012). Grounding citizenship: Toward a political psychology of public space. Political Psychology, 33, 123-143. doi: 10.1111/j.1467-9221.2011.00866.x

Di Masso, A. (2015). Micropolitics of public space: On the contested limits of citizenship as a locational practice. Journal of Social \& Political Psychology, 3, 63-83. doi: 10.5964/jspp.v3i2.322

Dixon, J., Levine, M., \& McAuley, R. (2006). Locating impropriety: Street drinking, moral order, and the ideological dilemma of public space. Political Psychology, 27, 187206. doi: 10.1111/j.1467-9221.2006.00002.x

Durrheim, K., \& Dixon, J. (2000). Theories of culture in racist discourse. Race \& Society, 3, 93-109. doi: 10.1016/S1090-9524(01)00024-9

Durrheim, K., Greener, R., \& Whitehead, K. A. (2015). Race trouble: Attending to race and racism in online interaction. British Journal of Social Psychology, 54, 84-99. doi: 10.1111/bjso. 12070

Dwyer, P. (2000). Welfare rights and responsibilities: Contesting social citizenship. Bristol: Policy Press.

Dwyer, P. (2004). Creeping conditionality in the UK: From welfare rights to conditional entitlements? Canadian Journal of Sociology, 29, 265-287. doi: $10.1353 /$ cjs.2004.0022

Dwyer, P., \& Wright, S. (2014). Universal credit, ubiquitous conditionality and its implications for social citizenship. Journal of Poverty \& Social Justice, 22, 27-35. doi: 10.1332/175982714X13875305151043

Edwards, D., \& Mercer, N. (1987). Common knowledge: The development of understanding in the classroom. London: Routledge.

Edwards, D., \& Potter, J. (1992). Discursive psychology. London: Sage. 
'Election 2015 results'. (2015). BBC News. Retrieved from http://www.bbc.co.uk/news/election/2015/results

English, R. (2011, March 1). The EU charter: Are we in or out? [Web log post]. Retrieved from http://ukhumanrightsblog.com/2011/03/01/the-eu-charter-are-we-in-or-out/ European Union. (2007). On the application of the charter of fundamental rights of the European Union to Poland and the United Kingdom. Official Journal of the European Union. Retrieved from http://eurlex.europa.eu/LexUriServ/LexUriServ.do?uri=OJ:C:2007:306:0156:0157:EN:PDF

Figgou, L. (2015). Constructions of 'illegal' immigration and entitlement to citizenship: Debating an immigration law in Greece. Journal of Community \& Applied Social Psychology. Advance online publication. doi: 10.1002/casp.2242

Ford, R., \& Goodwin, M. (2014). Revolt on the right: Explaining support for the radical right in Britain. Abingdon: Routledge.

Furnham, A. (1982). Explanations for unemployment in Britain. European Journal of Social Psychology, 12, 335-352. doi: 10.1002/ejsp.2420120402

Gibson, S. (forthcoming). Policing the boundaries in an online discussion forum.

Gibson, S., \& Booth, R. (forthcoming). ‘An Australian-style points-based system’: Individualizing immigration in radical right discourse.

Gibson, S. (2009). The effortful citizen: Discursive social psychology and welfare reform. Journal of Community \& Applied Social Psychology, 19, 393-410. doi: 10.1002/casp.1003

Gibson, S. (2011). Dilemmas of citizenship: Young people's conceptions of un/employment rights and responsibilities. British Journal of Social Psychology, 50, 450-468. doi: 10.1348/014466610X520113 
Gibson, S. (2015). Constructions of 'the Polish' in Northern England: Findings from a qualitative interview study. Journal of Social \& Political Psychology, 3, 43-62. doi: 10.5964/jspp.v3i2.414

Gibson, S., \& Hamilton, L. (2011). The rhetorical construction of polity membership: Identity, culture and citizenship in young people's discussions of immigration in northern England. Journal of Community \& Applied Social Psychology, 21, 228-242. doi: 10.1002/casp.1087

Gibson, S., \& Hamilton, L. (2013). Knowledge, autonomy and maturity: Developmental and educational concerns as rhetorical resources in adolescents' discussions regarding the age of electoral majority in England. Journal of Youth Studies, 16, 34-53. doi: $10.1080 / 13676261.2012 .693589$

Giddens, A. (1998). The third way: The renewal of social democracy. Cambridge: Polity.

Giles, D. C. (2016). Observing real-world groups in the virtual field: the analysis of online discussion. British Journal of Social Psychology. Advance online publication. doi: 10.1111/bjso.12139

Goodman, S. (2014). Developing an understanding of race talk. Social and Personality Psychology Compass, 8, 147-155. doi: 10.1111/spc3.12095

Goodman, S., \& Rowe, L. (2014). 'Maybe it is prejudice ... but it is NOT racism': Negotiating racism in discussion forums about Gypsies. Discourse \& Society, 25, 115. doi: $10.1177 / 0957926513508856$

Gray, D., \& Griffin, C. (2014). A journey to citizenship: Constrcutions of citizenship and identity in the British citizenship test. British Journal of Social Psychology, 53, 299314. doi: $10.1111 /$ bjso. 12042

Haste, H. (2004). Constructing the citizen. Political Psychology, 25, 413-439. DOI: 10.1111/j.1467-9221.2004.00378.x 
Hodgetts, D., \& Griffin, C. (2015). The place of class: Considerations for psychology. Theory \& Psychology, 25, 147-166. doi: 10.1177/0959354315576381

Hopkins, N., \& Blackwood, L. (2011). Everyday citizenship: Identity and recognition. Journal of Community \& Applied Social Psychology, 21, 215-227. doi: 10.1002/casp.1088

House rules. (n.d.). BBC Moderation. Retrieved from http://www.bbc.co.uk/social/moderation/house-rules

Isin, E. F., \& Wood, P. K. (1999). Citizenship and identity. London: Sage.

Jefferson, G. (1990). List-construction as a task and resource. In G. Psathas (Ed.), Interaction competence (pp.63-92). Lanham, MD: University Press of America.

Jowett, A. (2015). A case for using online discussion forums in critical psychological research. Qualitative Research in Psychology, 12, 287-297. doi: $10.1080 / 14780887.2015 .1008906$

Kessler-Harris, A. (2003). In pursuit of economic citizenship. Social Politics, 10, 157-175. doi: $10.1093 / \mathrm{sp} / \mathrm{jxg} 008$

Lister, R. (2002). Towards a new welfare settlement? In C. Hay (Ed.), British politics today (pp. 127-156). Cambridge: Polity.

Lund, B. (1999). 'Ask not what your community can do for you': Obligations, New Labour and welfare reform. Critical Social Policy, 19, 447-462. doi:

Loredo-Narciandi, J. C., \& Castro-Tejerina, J. (2013). Citizen Weeks of the psychologizing of citizenship. History of Psychology, 16, 57-71. doi: 10.1037/a0031317

Lynn, N., \& Lea, S. (2003). 'A phantom menace and the new apartheid': The social construction of asylum seekers in the United Kingdom. Discourse \& Society, 14, 425-452. doi: 10.1177/0957926503014004002 
Marshall, T. H. (1992). Citizenship and social class. In T. H. Marshall, \& T. Bottomore Citizenship and social class (pp. 1-51). London: Pluto. (Original work published 1950).

Pomerantz, A. M. (1984). Giving a source or basis: The practie in conversation of telling 'how I know'. Journal of Pragmatics, 8, 607-625. doi: 10.1016/03782166(84)90002-X

Pomerantz, A. M. (1986). Extreme case formulations: A way of legitimizing claims. Human Studies, 9, 219-229. doi: 10.1007/BF00148128

Potter, J. (1996). Representing reality: Discourse, rhetoric and social construction. London: Sage.

Potter, J., \& Hepburn, A. (2005). Qualitative interviews in psychology: Problems and possibilities. Qualitative Research in Psychology, 2, 281-307. doi: 10.1191/1478088705qp045oa

Potter, J., \& Wetherell, M. (1987). Discourse and social psychology: Beyond attitudes and behaviours. London: Sage.

Reicher, S. (1997). Laying the ground for a common critical psychology. In T. Ibáñez \& L. Íñigeuz (Eds.), Critical social psychology (pp. 83-94). London: Sage.

Rees, A. M. (1995). The other T. H. Marshall. Journal of Social Policy, 24, 341-362. doi: $10.1017 / \mathrm{S} 0047279400025150$

Riley, S., Morey, Y., \& Griffin, C. (2010). The ‘pleasure citizen’: Analyzing partying as a form of social and political participation. Young: Nordic Journal of Youth Research, 18, 33-54. doi: 10.1177/110330880901800104

Rose, N. (2000). Community, citizenship, and the third way. American Behavioral Scientist, 43, 1395-1411. doi: 10.1177/00027640021955955 
Rowe, L., \& Burke, S. (2015). The benefits of using discourse analysis in online data. QMIP Bulletin, 19, 8-16.

Sakki, I., \& Pettersson, K. (2015). Discursive constructions of otherness in populist radical right political blogs. European Journal of Social Psychology. Advance online publication. doi: 10.1002/ejsp.2142

Shotter, J. (1993). Psychology and citizenship: Identity and belonging. In B. S. Turner (Ed.), Citizenship and social theory (pp. 115-138). London: Sage.

Stenner, P., \& Taylor, D. (2008). Psychosocial welfare: Reflections on an emerging field. Critical Social Policy, 28, 415-437. doi: 10.1177/0261018308095278

Stevenson, C., Dixon, J., Hopkins, N., \& Luyt, R. (2015). The social psychology of citizenship, participation and social exclusion: Introduction to the special thematic section. Journal of Social \& Political Psychology, 3, 1-19. doi: 10.5964/jspp.v3i2.579

Taylor-Gooby, P. (2012). Root and branch restructuring to achieve major cuts: The social policy programme of the 2010 UK coalition government. Social Policy \& Administration, 46, 61-82. doi: 10.1111/j.1467-9515.2011.00797.x

'UK European election results'. (2014). BBC News. Retrieved from http://www.bbc.co.uk/news/events/vote2014/eu-uk-results

United Kingdom Independence Party. (2015). Believe in Britain: UKIP manifesto 2015. Retrieved from https://d3n8a8pro7vhmx.cloudfront.net/ukipdev/pages/1103/attachments/original/142 9295050/UKIPManifesto2015.pdf?1429295050

Viewpoints: How might Romanian and Bulgarian immigration affect the UK? (2013, August 16). BBC News. Retrieved from http://www.bbc.co.uk/news/uk-23712988 
Vicol, D.-O., \& Allen, W. (2014). Bulgarians and Romanians in the British national press: 1 December 2012 - 1 December 2013. Retrieved from University of Oxford, The Migration Observatory website: http://migrationobservatory.ox.ac.uk/reports/bulgarians-and-romanians-britishnational-press

Walby, S. (2003). The myth of the nation-state: Theorizing society and polities in a global era. Sociology, 37, 529-546. doi: 10.1177/00380385030373008

Wetherell, M. (2003). Racism and the analysis of cultural resources in interviews. In H. van den Berg, M. Wetherell, \& H. Houtkoop-Steenstra (Eds.), Analyzing race talk: Multidisciplinary approaches to the interview (pp. 11-30). Cambridge: Cambridge University Press.

Wetherell, M., \& Potter, J. (1988). Discourse analysis and the identification of interpretative repertoires. In C. Antaki (Ed.), Analysing everyday explanation: A casebook of methods (pp. 168-183). London: Sage.

Wetherell, M., \& Potter, J. (1992). Mapping the language of racism: Discourse and the legitimation of exploitation. Hemel Hempstead: Harvester Wheatsheaf.

Wintour, P. (2015, October 22). Iain Duncan Smith to trial benefit sanction warning. The Guardian. Retrieved from http://www.theguardian.com/money/2015/oct/22/benefitsanction-warning-period-to-be-trialled

Wood, C., \& Finlay, W, M. L. (2008). British National Party representations of Muslims in the month after the London bombings: Homogeneity, threat, and the conspiracy tradition. British Journal of Social Psychology, 47, 707-726. doi: $10.1348 / 014466607 X 264103$ 


\section{Footnotes}

i The term 'nation-state' is in scare quotes here to signal the problematic status of the idea of the nation-state in practice (Walby, 2003). Indeed, the UK is a good example of such problems, with attempts to forge notions of British identity being examples of projects designed to secure governance of an ethnically diverse multi-nation state (Colley, 1992; Condor, 2011b).

${ }^{\text {ii }}$ Comments are presented as they appeared on the discussion forum, with no attempt to correct spelling, grammatical or other errors. 